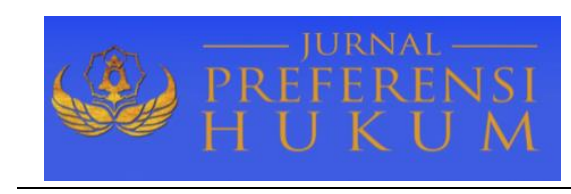

Jurnal Preferensi Hukum | ISSN: XXXX | E-ISSN: XXXX

Vol. 1, No. 2 - September 2020, Hal. 1-5| Available Online at https://www.ejournal.warmadewa.ac.id/index.php/juprehum

DOI: http://doi.org/10.22225/jph.v1i2.2369.1-5

\title{
PERLINDUNGAN HUKUM TERHADAP ANAK DI BAWAH UMUR YANG MENJADI KORBAN TINDAK PIDANA PERSETUBUHAN (Berdasarkan Putusan Nomor 58/Pid.Sus/2015/Pn.Tab)
}

\author{
Agustinus Yitsak Mannuel Kapitan, I Made Sepud, I Nyoman Sujana \\ Fakulats IImu Hukum Universitas Warmadewa, Denpasar - Bali, Indonesia
}

\begin{abstract}
Abstrak
Perlindungan hukum merupakan upaya hukum yang harus diberikan oleh aparat penegak hukum untuk memberikan rasa aman kepada masyarakat baik bagi jiwa maupun raga dari gangguan dan ancaman dari pihak manapun. Perlindungan anak korban tindak pidana moral diatur dalam Undang-Undang Nomor 23 Tahun 2002 jo dan Undang Undang Nomor 35 Tahun 2014 Tentang Perlindungan Anak. Penelitian ini dilakukan dengan tujuan mendeskripsikan bagaimana perlindungan hukum terhadap anak yang menjadi korban tindak pidana persetubuhan dan apa sanksi pidana terhadap pelaku tindak pidana persetubuhan pada anak. Penelitian ini dilakukan dengan menggunakan metode penelitian hukum normatif. Berdasarkan hasil penelitian dan pembahasannya, perlindungan hukum terhadap anak yang menjadi korban tindak pidana persetubuhan diatur dalam UU No. 35 Tahun 2014. Anak yang menjadi korban diberikan perlindungan baik berupa bantuan medis, rehabilitasi-psiko, hak atas restitusi hak atas kompensasi, atau ganti rugi. Sanksi pidana terhadap pelaku tindak pidana persetubuhan anak dalam putusan nomor 58/Pid.Sus/2015/PN.Tab pelaku dijatuhkan 7 (tujuh) tahun hukuman penjara dan denda sebesar 150.000.000.00. Melihat perbuatan korban yang sangat kejam, merampas kehormatan orang lain yaitu anaknya sendiri, hukuman yang patut diberikan kepada pelaku adalah hukuman maksimal. Apabila denda tersebut tidak dapat dibayar maka masa hukuman terdakwa ditambah menjadi 6 (enam) bulan.
\end{abstract}

Kata kunci: Anak; Korban Tindak Pidana Persetubuhan; Perlindungan hukum

\begin{abstract}
Legal protection is a legal effort that must be provided by law enforcement officials to provide a sense of security to the community both body and soul from interference and threats from any party. The protection of children who are victims of moral crimes is regulated in Law Number 23 of 2002 jo and Law Number 35 of 2014 concerning Child Protection. This research was conducted with the aim of describing the legal protection of a child who is the victim of criminal acts of sexual intercourse and the criminal sanctions against the perpetrators of the sexual intercourse crime on a child. This research was conducted using the normative legal research method. Based on the results of the research and discussion, the legal protection for children who are victims of criminal acts of intercourse is regulated in Law No. 35/2014. Children who are victims are given protection in the form of medical assistance, psycho-rehabilitation, the right to restitution, the right to compensation. Criminal sanctions against the perpetrator of the criminal act of child sexual intercourse in decision number 58 / Pid.Sus / 2015 / PN.Tab, the perpetrator was sentenced to 7 (seven) years in prison and a fine of 150,000,000.00. Seeing the perpetrator's actions were very cruel, robbing other people's honor, namely his own daughter, the punishment that should be given to the perpetrator is the maximum punishment. If the fine cannot be paid, the defendant's sentence will be increased to 6 (six) months.
\end{abstract}

Keywords: Child; Victims of the Crime of Sexual Intercourse; Legal Protection

\section{PENDAHULUAN}

Anak merupakan penerus generasi bangsa. Oleh karena itu, komitmen dan perlakuan yang memperhatikan perkembangan dan peranan generasi anak sebagai penerus bangsa merupakan suatu hal yang harus dipegang pemerintah. Anak yang belum matang secara mental dan fisik, kebutuhannya harus dicukupi, pendapatnya harus dihargai, dan diberikan pendidikan yang benar dan kondusif bagi pertumbuhan dan perkembangan pribadi dan kejiwaannya, agar dapat berkembang dan tumbuh menjadi anak yang dapat diharapkan sebagai penerus bangsa (Fauzi, 2019; Sakerebau, 2018). 
Kekerasan seksual terhadap anak sering terjadi akhir-akhir ini (Krisnani \& Kessik, 2020; Ningsih \& Hennyati, 2018; Noviana, 2015; Sari, Nulhaqim, \& Irfan, 2015). Anak merupakan anugrah yang tidak ternilai yang dikaruniakan oleh tuhan untuk setiap pasangan. Anak harus didik, dilindungi, dan dipelihara (Chazawi, 2005). Sebagaimana pada umumnya UU perlindungan anak guna diperlukan memberikan perlindungan terhadap hak-hak anak, memberikan jaminan dan kepastian hukum dikarenakan anak adalah:

1. amanat dan Karunia Tuhan yang Maha Esa,

2. penerus cita-cita perjuangan Bangsa dan Negara dimasa depan,

Anak perlu mendapatkan kesempatan seluas-luasnya untuk berkembang dan tumbuh secara optimal, baik secara mental, fisik, dan mempunyai akhlak yang mulia maupun sosial. Pada kenyataan banyak anak yang mendapat kekerasan dan eksploitasi, tidak mendapatkan pendidikan yang wajar dan memadai, masih banyak anak yang terlantar, dan belum mendapatkan perlindungan (Hidayat \& Mahyani, 2017).

Dari latar belakang di atas penelitian ini dilakukan dengan tujuan mendeskripsikan bagaimana perlindungan hukum terhadap anak yang menjadi korban tindak pidana persetubuhan dan apa sanksi pidana terhadap pelaku tindak pidana persetubuhan pada anak.

\section{METODE PENELITIAN}

Penelitian ini didesain dengan menggunakan metode penelitian hukum normatif. Artinya penelitian ini mengkaji aspek sejarah, teori, struktur, perbandingan, filosofis, komposisi, materi, pasal-pasal dan penjelasan umum. Pendekatan masalah yang digunakan adalah pendekatan konseptual dan pendekatan perundang-undangan.

Sumber data penelitian ini adalah bahan hukum primer, yaitu catatan-catatan resmi serta peraturan perundang-undangan dan bahan hukum skunder, yaitu tulisan para para ilmuan dan para ahli yang berbentuk karya ilmiah atau makalah. Adapun metode pengumpulan bahan hukum yang dilakukan adalah dengan mencatat, dokumentasi file, mengutip, menganalisa yang artinya bahan hukum yang dikumpulkan diklasifikasikan sesuai dengan jenis bahan hukum yang digunakan. Analisa bahan hukum disajikan secara deskritif yaitu dengan cara menyusun bahan hukum secara sistematis sehingga membentuk suatu karya ilmiah.

\section{HASIL DAN PEMBAHASAN}

\section{Perlindungan Hukum terhadap Anak yang Menjadi Korban Tindak Pidana Persetubuhan}

Anak adalah seseorang perempuan atau laki-laki yang belum mengalami masa pubertas atau belum dewasa, dimana "anak" merujuk pada lawan dari orang tua. Orang dewasa adalah anak dari orang tua, dimana umur anak banyak dikategorikan dalam UU. Dalam hal ini menurut psikologi, periode perkembangan anak dari masa bayi hingga usia lima tahun enam bulan, biasanya periode ini disebut periode prasekolah. Kemudian berkembang dengan tahun sekolah dasar.

Di Indonesia penjelasan mengenai anak banyak dikemukakan oleh para ahli (Sujana, 2015). UU hukum perdata pasal 330 ayat (1) seseorang yang belum mencapai 21 tahun, UU hukum pidana pasal 287 ayat (1) seseorang yang belum mencapai 15 tahun, UU no. 35 tahun 2014 dalam pasal 1 butir 1 kategori anak adalah seseorang yang belum mencapai 18 tahun, UU kesejahteraan anak No. 4 tahun 1979 pasal 1 ayat (2) seseorang yang belum mecapai 21 tahun, UU No. 39 tahun 1999 pasal 1 sub 5 seseorang yang belum mencapai 18 tahun. Dalam peraturan perundang-undangan di Indonesia sangat banyak dikategorikan sebagai seseorang anak tergantung situasi dan kondisi dalam sudut pandang yang dipersoalkan.

Korban adalah seseorang yang mengalami penderitaan mental atau fisik, atau mengalami kematian atas perbuatan, kerugian harta benda. Jadi, dalam hal ini "orang yang mendapatkan penderitaan fisik dan seterusnya"itu adalah korban dari tindak pidana (Bambang Waluyo,2024:9). Selanjutnya, secara yuridis pengertian korban termasuk dalam UU No. 13 tahun 2006 serta UU No. 23 tahun 2004 dan UU no. 27 tahun 2004. Hak-haknya dan masalah perlindungannya dalam melindungi anak-anak Indonesia. Hak-hak anak agar dalam perlindungan hukum dapat dilakukan secara teratur, tertib dan bertanggungjawab, maka diperlukan peraturan hukum yang selaras dengan perkembangan masyarakat Indonesia yang dijiwai sepenuhnya oleh pancasila dan UUD 1945. Oleh karena itu, dalam UUD 1945 pada pasal 34 telah ditegaskan bahwa "fakir miskin dan anak-anak terlantar dipelihara oleh Negara". 
Menurut Satjipto Raharjo, perlindungan hukum adalah memberikan pengayoman terhadp hak asasi manusia (HAM) yang dirugikan orang lain, dan perlindungan itu diberikan kepada masyarakat agar dapat menikmati semua hak-hak yang diberikan oleh hukum. Pasal 2 UU No. 35 Tahun 2014 bahwa penyelenggaran perlindungan anak harus berasaskan pancasila dan berlandaskan UUD 1945 mengenai apa saja yang menjadi prinsip hak anak, yaitu:

1. non diskriminasi;

2. kepentingan yang terbaik bagi anak;

3. hak untuk hidup, kelangsungan hidup, dan perkembangan; dan

4. penghargaan terhadap pendapat anak.

Penerapan perlindungan hak-hak korban kejahatan dengan mengacu pada hak asasi yang bersangkutan sebagai akibat dari terselenggaranya penerapan perlindungan korban, maka beberapa teori perlindungan korban kejahatan dapat dilihat dari (Mansur, 2007):

1. teori Utulitas,

2. teori Tanggung Jawab,

3. teori Ganti Kerugian.

Beberapa asas hukum Perlindungan terhadap korban kejahatan memerlukan, baik hukum pidana formiil maupun hukum pidana materiil, dalam hal ini yang dimaksud adalah:

1. asas Kepastian Hukum,

2. asas Keseimbangan,

3. asas Manfaat, dan

4. asas keadilan.

Bentuk-bentuk perlindungan korban kejahatan dapat memberikan retribusi dan kompensasi, pelayanan, konseling/bantuan hukum, bantuan medis, Yang terpenting di atas adalah lembagalembaga perlindungan korban harus lebih memperhatikan hak-hak korban (R Waluyo,2006:78).

\section{Sanksi Pidana terhadap Pelaku Tindak Pidana Persetubuhan pada Anak}

Mengenai putusan Nomor 58/Pid.Sus/2015/PN.Tab dalam kasus, terdakwa Syaiful terangsang melihat korban, Putri Stevani, yang menggunakan celana pendek saat tidur sehingga menimbulkan keinginan atau nafsu untuk melakukan kejahatan yaitu melakukan persetubuhan dengan anak tirinya sendiri. Adapun beberapa faktor-faktor penyebab terjadinya kejahatan persetubuhan dimaksud. Kejahatan persetubuhan dalam hal ini harus melihat dari segala aspek terhadap anak di bawah umur dapat terjadi karena bertemunya faktor internal dan eksternal dalam diri pelaku maupun dalam diri korban. faktor internal adalah faktor yang terdapat pada diri seseorang pelaku maupun korban. Pada kasus persetubuhan misalnya sikap dan tindakan korban yang menyebabkan rangsangan sehingga pelaku terpancing untuk melakukan persetubuhan, contohnya:

1. Pelaku tidak dapat menahan nafsunya dan tidak dapat mengontrol emosinya,

2. Adanya prilaku yang menyimpang yaitu kejiwaan dalam diri pelaku maupun korban,

3. Ketaatan dalam menjalankan perintah agama yang masih kurang baik,

4. Keadaan keluarga yang tidak harmonis.

Sedangkan faktor eksternal adalah lingkungan atau tempat tinggal dimana pelaku dan korban (anak) sangat berpengaruh terhadap terjadinya kejahatan persetubuhan. Biasanya pelaku persetubuhan melakukan kejahatan di tempat sepi tau gelap melihat korban yang berada sendiri di tempat tersebut, adanya faktor kesempatan, dan kamar tidur yang tidak memiliki pembatas antara korban dan pelaku, sehingga kemungkinan besar persetubuhan dapat terjadi. Adapun contoh lainnya, yaitu:

1. Faktor teknologi,

2. Perkembangan budaya yang tidak lagi beretika dalam berpakaian yang dapat merangsang pihak lain.

Dalam putusan 58/Pid.Sus/2015/PN Tab dakwaan penuntut umum terhadap terdakwa Syaiful yang melakukan persetubuhan sebagaiman diatur dan diancam pidana pasal 81 ayat (1) UU no. 35 tahun 2014 jo UU no. 23 tahun 2002 tentang perlindungan anak yang dalam hal ini mempunyai unsur yang pertama 1. Setiap orang, 2. Melanggar ketentuan sebagaimana dimaksud dalam pasal 76D unsur yang kedua 1. Setiap Orang, 2. Melanggar ketentuan sebagaimana dimaksud dalam pasal 76E.

Dalam hal ini jika dikaitkan dengan putusan 58/Pid.Sus/2015/PN.Tab tentang pidana persetubuhan yang dilakukan oleh ayah tiri, berdasarkan penjelasan yang tertuang dalam putusan tersebut, terdakwa melakukan persetubuhan tersebut karena terangsang melihat korban, Putri Stevani, 
yang sedang tertidur menggunakan celana pendek sehingga timbul niat jahat untuk melakukan kejahatan persetubuhan. Terdakwa dalam putusan ini secara sah dan bertanggung jawab melakukan tindak pidana persetubuha. Hal ini dapat dilihat dari unsur-unsur yang sesuai pertimbangan hakim telah terpenuhi yang ada dalam pasal 82 ayat (1) UU no. 35 tahun 2014 tentang perlindungan anak yaitu: 1. Setiap Orang, 2. Melanggar ketentuan sebagaimana dimaksud dalam pasal 76E.

Bahwa Terdakwa dengan saksi korban, Putri Stevani, yang saat itu masih berumur 15 (lima belas tahun) sesuai dengan yang tertera di ijazah merupakan anak tiri dari terdakwa. Sekira bulan April 2015 terdakwa kost dan menyewa 1 (satu) kamar tidur di Banjar Sema, Desa Kedri, Kecamatan Kediri, Kabupaten Tabanan bersama dengan istri, ketiga anak terdakwa, serta saksi Putri Stevani. Kemudian pada bulan Mei 2015 sekitar pukul 21.00 WITA terdakwa bersama dengan istri, ketiga anak terdakwa, dan saksi korban, Putri Stevani, tidur dalam 1 kamar tidur dimana saksi korban Putri Stevani bersama dengan ketiga anak terdakwa tidur diatas tempat tidur sedangkan terdakwa bersama dengan istri terdakwa tidur dilantai beralaskan kasur spon. Sekitar pukul 05.00 WITA terdakwa bangun kemudian terdakwa kencing ke kamar mandi saat balik dari kamar mandi terdakwa terangsang melihat saksi korban Putri Stevani tidur dengan menggunakan celana pendek namun terdakwa kembali tidur disamping istri terdakwa. Sekitar pukul 05.30 WITA istri terdakwa keluar kamar selanjutnya terdakwa bangun dan mematikan lampu kamar tidur kemudian terdakwa mendekati saksi korban Putri Stevani dan duduk di atas tempat tidur samping kanan saksi korban Putri Stevani. Selanjutnya, terdakwa meraba paha kanan dan kiri saksi korban Putri Stevani. Kemudian, terdakwa meraba payudara saksi korban Putri Stevani. Setelah itu, saksi Korban Putri Stevani bangun dan berkata "Bapak ngapain pak" dan saksi korban Putri Stevani memeberontak tapi kedua kaki saksi korban Putri Stevani di tindih kedua kaki terdakawa kemudian mendorong kepala saksi korban Putri Stevani hingga memebentur dinding kamar kost sambil terdakwa berkata "Diam saja nanti saya pukul". Selanjutnya, terdakwa menindih tubuh saksi korban Putri Stevani, lalu terdakwa memasukkan tangan kanan terdakwa ke dalam celana dalam saksi korban Putri Stevani, selanjutnya memasukkan jari tengah ke dalam vagina saksi korban Putri Stevani, dan menggerakkannya sehingga terdakwa menjadi terangsang. Kemudian, terdakwa menaikkan baju saksi korban Putri Stevani dan melorotkan celana pendek sampai ke paha, lalu terdakwa mengikat sarung yang terdakwa pakai saat itu di pinggang, dan terdakwa memasukkan alat kelamin terdakwa ke dalam lubang vagina saksi korban Putri Stevani. Kemudian, terdakwa menggerakkannya selama kurang lebih lima menit, dan akhirnya terdakwa mengeluarkan sperma di paha saksi korban Putri Stevani. Setelah itu, terdakwa keluar kamar.

Akibat dari perbuatan terdakwa, saksi korban Putri Stevani mengalami robekan lama pada Hymen jam 5 dan 6 . Hal tersebut kemungkinan karena adanya benturan benda keras dan tumpul (sesuai dengan visum Et Revertum Nomor.370/319/15/BRSU Tabanan tanggal 20 Agustus yang diperiksa oleh ( dr.Ni Wayan Lusidarini ) badan Rumah sakit Umum Tabanan).

Dengan terpenuhinya semua unsur-unsur tersebut, maka Hakim menjatuhkan pidana kepada terdakwa 7 (tujuh) tahun dan denda sebesar Rp.150.000.000.00 dan apabila denda tersebut tidak dapat dibayar maka masa hukuman terdakwa ditambah atau menjadi 6 (enam) bulan.menurut penulis putusan ini sudah tepat dan cukup akan memberikan efek jera bagi terdakwa, memperbaiki mental terdakwa, dan terdakwa menyadari akibat dari perbuatannya agar supaya terdakwa tidak berkeinginan lagi untuk mengulangi perbuatannya di kemudian hari.

\section{SIMPULAN DAN SARAN \\ 1. Simpulan}

Perlindungan hukum terhadap korban tindak pidana persetubuhan anak diatur dalam UU No. 35 tahun 2014. Dalam hal ini anak yang menjadi korban diberikan perlindungan baik berupa bantuan medis, rehabilitasi-psiko, hak atas restitusi hak atas kompensasi, atau ganti rugi. Akan tetapi penerapan terhadap Undang-undang perlindungan anak dikatakan masih belum maksimal karena tidak mendapat rasa keadilan bagi anak atau korban, dalam hal ini penyelesaian perkara pidana kejahatan persetubuhan khususnya kurang memperoleh perlindungan hukum yang memadai baik perlindungan yang sifatnya materiil maupun immaterial sering kali korban dijadikan sebagai saksi dalam persidangan sebagai pemenuh Undang-Undang saja hal ini mengakibatkan peluang untuk mendapatkan hak-hak anak menjadi sangat kecil. 
Sanksi pidana terhadap pelaku tindak pidana persetubuhan anak dalam putusan Nomor 58/Pid.Sus/2015/PN.Tab pelaku diberikan 7 (tujuh) tahun penjara dan denda sebesar 150.000.000.00. Melihat perbuatan korban yang sangat kejam merampas kehormatan orang lain yaitu anaknya sendiri, hukuman yang patut diberikan kepada pelaku adalah hukuman maksimal.

\section{Saran}

Kepada pemerintah agar lebih memperhatikan hak-hak anak dan perlindungan korban anak, agar anak yang menjadi korban tindak pidana mendapat perlindungan hukum, mendapat bantuan medis, rehabilitasi-psiko, hak atas restitusi hak atas kompensasi, atau ganti rugi. Sebelumnya korban (anak) hanya sebagai pemenuh Undang-Undang saja, sebatas sebagai saksi di pengadilan. Masyarakat dan orang tua harus lebih memberikan pendidikan setinggi-tingginya dan pemahaman nilai-nilai agama kepada anak.

\section{DAFTAR PUSTAKA}

Chazawi, A. (2005). Tindak Pidana Mengenai Kesopanan. Jakarta: Rajawali Pers.

Fauzi, R. (2019). Pelaksanaan Penanganan Penyidikan Tindak Pidana Persetubuhan dan Pencabulan terhadap Anak di Polsek Empat Angkaat Candung. Jurnal Cendekia Hukum, 5(1), 173-184.

Hidayat, S., \& Mahyani, A. (2017). Perlindungan Hukum bagi Anak Korban Eksploitasi sebagai Artis. Mimbar Keadilan Jurnal Ilmu Hukum, 229-238.

Krisnani, H., \& Kessik, G. (2020). Analisis Kekerasan Seksual pada Anak dan Intervensinya oleh Pekerjaan Sosial (Studi Kasus Kekerasan Seksual oleh Keluarga di Lampung). Focus: Jurnal Pekerjaan Sosial, 2(2), 198-207.

Mansur, D. M. A. (2007). Urgensi perlindungan korban kejahatan. Jakarta: PT Raja Grafindo Persada.

Ningsih, E. S. B., \& Hennyati, S. (2018). Kekerasan Seksual pada Anak di Kabupaten Karawang. Midwife Journal, 4(2), 56-65.

Noviana, I. (2015). Kekerasan Seksual terhadap Anak: Dampak dan Penanganannya. Sosio Informa, $1(1), 13-28$.

Sakerebau, J. (2018). Memahami Peran Psikologi Pendidikan bagi Pembelajaran. BIA': Jurnal Teologi Dan Pendidikan Kristen Kontekstual, 1(1), 96-111.

Sari, R., Nulhaqim, S. A., \& Irfan, M. (2015). Pelecehan Seksual terhadap Anak. Prosiding Penelitian Dan Pengabdian Kepada Masyarakat, 2(1), 14-18.

Sujana, I. N. (2015). Kedudukan Hukum Anak Luar Kawin dalam perspektif Putusan Mahkamah Konstitusi Nomor 46/PUU-VIII/2010. 